\title{
Implementation of Safety Performance Framework (SPF) In Process Industries to Avoid Disasters
}

\author{
M. Y. Shamim ${ }^{1}$, A. Buang ${ }^{1 *}$, A. M. Shariff ${ }^{1}$ and H. Anjum² \\ ${ }^{1}$ Centre of Advanced Process Safety (CAPS), Department of Chemical Engineering, \\ Universiti Teknologi PETRONAS (UTP), \\ 32610 Seri Iskandar, Perak Darul Ridzuan, Malaysia \\ *Email: azizul.buang@utp.edu.my \\ Phone: +605-3687627; Fax: +605-3656176 \\ ${ }^{2}$ Department of Chemical Engineering, Universiti Teknologi PETRONAS (UTP), \\ 32610 Seri Iskandar, Perak Darul Ridzuan, Malaysia
}

\begin{abstract}
The reports of past major process disasters reveal that catastrophes are preventable and many of the problems are recognized prior to the accidents through the near-misses. The key element to improve safety performance is analyzing the performance indicators i.e. leading and lagging metrics in order to avoid process disasters. In past, the focus has only been given to the implementation of fourteen elements of process safety management (PSM) system, legislated under occupational safety and health administration (OSHA), for the effective safety system. However, it ignored the insight behaviour and performance of indicators along with its associated metrics for its every element. Therefore, to cater all these needs, a structured technique known as safety performance framework (SPF) has been suggested. It encompasses four major steps including a developed mathematical model i.e. safety performance index (SPI) to ensure the proper implementation of PSM in process industries. In addition to this, the identification of leading and lagging indicators for each PSM element is an integral part of this structure and is the real key to success. Moreover, this technique has been applied to the case studies of current process plant and the past disaster, where it has disclosed the insights of safety performance failure. Thus, SPF has been shown as a helpful tool to implement PSM in process industries to avoid disasters.
\end{abstract}

Keywords: Process safety management; process industry; performance indicators; SPF

\section{INTRODUCTION}

Due to the development of any country, the expansion of industry inevitably becomes the necessity. Such an expansion i.e. larger process plant size, complex automation system, new materials/chemicals etc. increases the potential for industrial disasters $[1,2]$. These disasters are usually occurred by the virtue of hazardous chemicals in the form of toxic, reactive, flammable, explosive, or a combination of these properties. There is always a possibility of disaster if accidental releases of those chemicals are not properly controlled and go unchecked. Safety for any process industry needs to be improved even if there is no human injuries or loss of work days witnessed in any accidental mishap. With the passage of time, disasters continued to occur frequently due to rapid industrialization and technological movement [3]. The history of process disasters dates back a long time ago. 
However, the notable disasters in the decade of 1980 to 1990 gave an evolution to process safety management (PSM) system [4]. The major disasters were the San Juan Ixhuatepec explosion, Mexico in 1984 caused 650 casualties and 6400 injuries followed by Bhopal disaster, India having more than 2,000 deaths [5, 6]. It also includes the Piper Alpha explosion in 1988 resulting in 167 deaths, the Pasadena disaster in 1989 resulting in 23 deaths and 132 injuries. Then, the BASF disaster, Cincinnati, in 1990 resulting in 2 deaths, and the IMC disaster, Sterlington, LA, resulting in 8 deaths and 128 injuries [7, 8]. These catastrophes drew national and international attention to the need for some solid steps to be taken regarding the improvement of industrial safety. Therefore, in 1990, occupational safety and health administration (OSHA) published a proposed standard, 'Process Safety Management (PSM) of Highly Hazardous Chemicals', containing requirements for the management of hazards associated with processes using highly hazardous chemicals to help assure safe and healthful workplaces. Finally, on February 24, 1992; OSHA issued the full text of its PSM standard, 29 code of federal regulations (CFR) 1910.119, including the list of covered chemicals and threshold amounts [9].

This standard mainly applies to manufacturing industries including chemicals, transportation equipment, natural gas liquids, farm product warehousing, and fabricated metal products. But it has some limitations to apply for the industrial facilities. It only applies to the facilities having flammable liquids and gasses in quantities of 10,000 pounds $(4535.9 \mathrm{~kg}$ ) or more [10]. Additionally, it does not apply to the retail facilities. As PSM is an integral part of process safety, therefore, since its inception, all worldwide process industries and regulatory bodies have acknowledged its importance and its brighter future in terms of saving human and capital assets from accidental losses [1113]. Moreover, there are total fourteen elements in it which are process safety information (PSI), process hazard analysis (PHA), operating procedures (OP), employee participation (EP), training, contractors, pre-startup safety review (PSSR), mechanical integrity (MI), hot work permit (HWP), management of change (MOC), incident investigation (II), emergency planning and response (EPR), compliance audits (CA), and trade secrets (TS) [14-16]. Table 1 shows the standard codes for each PSM element.

Table 1. Standard codes of PSM elements [17-20].

\begin{tabular}{lc}
\hline PSM Element & Standard Code \\
\hline EP & 29 CFR 1910.119 (c) \\
PSI & 29 CFR 1910.119(d) \\
PHA & 29 CFR 1910.119(e) \\
OP & 29 CFR $1910.119(\mathrm{f})$ \\
Training & 29 CFR $1910.119(\mathrm{~g})$ \\
Contractors & 29 CFR $1910.119(\mathrm{~h})$ \\
PSSR & 29 CFR $1910.119(\mathrm{i})$ \\
HWP & 29 CFR $1910.119(\mathrm{j})$ \\
MOC & 29 CFR $1910.119(\mathrm{k})$ \\
MI & 29 CFR $1910.119(\mathrm{l})$ \\
II & 29 CFR $1910.119(\mathrm{~m})$ \\
EPR & 29 CFR $1910.119(\mathrm{n})$ \\
CA & 29 CFR $1910.119(\mathrm{o})$ \\
TS & 29 CFR $1910.119(\mathrm{p})$ \\
\hline
\end{tabular}


These elements have been implemented in various industries across the globe but still, the disasters continue to occur [21]. The investigation of BP Texas City refinery explosion in March 2005 revealed the importance of process safety instead of occupational safety. Because before this disaster, occupational safety key performance indicators (KPIs) in shape of OSHA incidental/accidental rates were being used but still the tragedy happened in which more than 15 people expired, around 130 suffered severe injuries and financial loss was more than 106 million euros. Therefore, the paradigm changed from occupational safety to process safety [22-24].

According to center for chemical process safety (CCPS) guidelines, process safety is related to the prevention of incidents that meet four criteria which are (a) physical or chemical process involvement, (b) location within an industrial facility, (c) the exceeded minimum threshold limit, and (d) acute release [25]. However, despite the implementation of PSM in process industries, still, the tragedies continue to occur such as the explosion of liquefied petroleum gas (LPG) vessel in HPCL refinery, India in 1997 resulted in many causalities and property damage [26]. These types of catastrophes are happened due to the lack of proper performance indicators in terms of leading and lagging metrics. Because the role of leading or output indicators is to identify the deficiencies and weakness in the overall safety management system before an incident/accident occurs. They are the forward-looking set of metrics which indicate the performance of the key work processes, operating discipline, or layers of protection that prevent incidents [27]. Whereas, lagging or input indicators are the retrospective set of metrics that tell the postdisaster condition. These indicators are the most common that are used in the industry because they are clear and easy to be identified and measured. They are used to measure the safety events that already occurred including accidents, explosions, fires, and flammable or toxic material releases $[28,29]$. Therefore, this study has suggested a safety performance framework (SPF) incorporated with the identification of leading and lagging metrics for all the fourteen elements of PSM. Moreover, this technique has also set the in-house acceptance criteria for these indicators in order to review and improve the safety performance of the plant.

\section{METHODOLOGY}

\section{Development of Safety Performance Framework}

This paper proposes a simple structured technique i.e. safety performance framework (SPF) to ensure the proper implementation of process safety management (PSM) system. The present technique involves total four main steps as shown in Figure 1.

\section{Identification and Consensus Building Over Performance Metrics}

Firstly, the reports of past major process disasters have been taken into consideration as the base to analyze the PSM elements failures. Table 2 presents the list of some of the major process disasters against each decade.

The second step is regarding the identification of effective performance indicators in terms of leading and lagging metrics for each PSM element. After this, safety performance review is required after every quarter of a year in which performance indicators are judged according to in-house acceptance criteria. If it is up to the set criteria of the company then PSM will be implemented effectively. These two things comprise 
the steps 3 and 4 respectively. Conversely, if there is a deviation from the acceptability criteria then there would be a need for an intervention step in terms of some activity or task for improving safety performance. Moreover, in this study, the leading metrics for frequently failing PSM element have also been identified through the literature review and the consensus has been made through a survey tool. The reason for taking only leading metrics is that they predict the pre-disaster situation. The survey tool used for this purpose is Delphi technique which is very simple and manageable as compared to other techniques $[33,34]$. The primary objective of this technique is to reach the consensus among the panellists or respondents regarding the development of performance indicators which will be applicable to all process industries [35, 36]. Furthermore, the panellists are selected from the safety field having experience in academics and industrial sectors. Moreover, the three statistical terms usually to be measured in this technique are (a) the interquartile range, should be less than 1 , (b) the standard deviation, should be below 1.5, and (c) the $51 \%$ of respondents lying in the 'agree' and 'strongly agree' $[37,38]$.

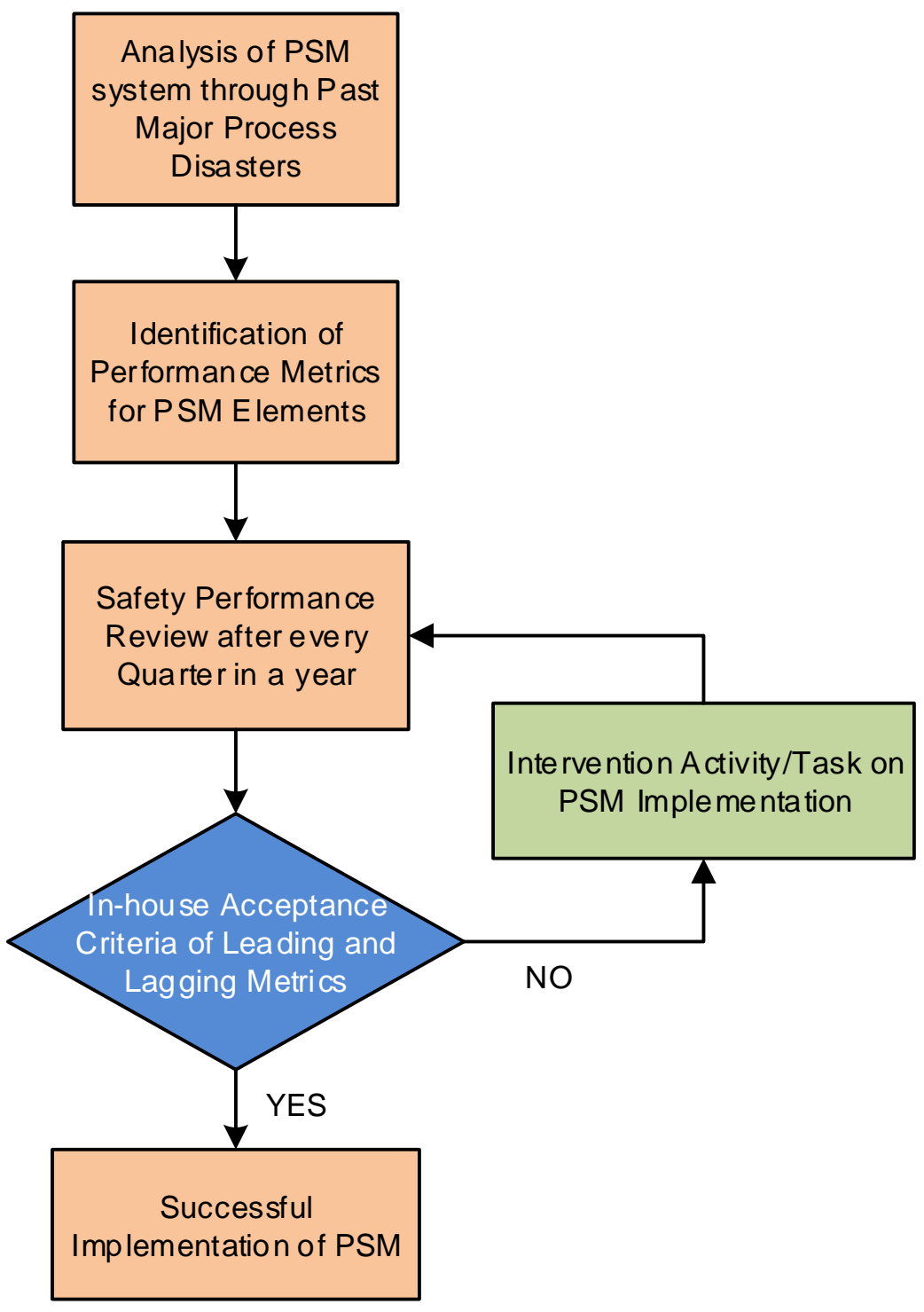

Figure 1. SPF for PSM implementation. 
Table 2. Major process disasters [30-32]

\begin{tabular}{cll}
\hline Decade & \multicolumn{1}{c}{ Disaster } & \multicolumn{1}{c}{ Chemical/Substance } \\
\hline 1970-1980 & Flixborough explosion, UK & Cyclohexane \\
& Seveso Toxic release, Italy & TCDD \\
& Texas city fire, USA Bhopal & Butane \\
& explosion, India & Methyl-Isocyanate \\
1981-1991 & Cubatao fire and toxic & Gasoline \\
& release, Brazil & LPG \\
& San Juan Ixhuatepec & Hydrogen \\
& explosion, Mexico Pasadena & Ethylene \\
& explosion, USA & Ethylene/Iso-Butane \\
& BASF explosion, USA IMC & \\
& explosion, USA & \\
& Vishakhapatnam refinery fire & LPG \\
& and explosion, India & \\
BP Texas City refinery & Hydrocarbons \\
2001-2016-2000 & Oil \\
& explosion, USA & \\
& Buncefield oil terminal & \\
& explosion, UK & Ammonium Nitrate \\
& West Fertilizer Company & \\
& (WFC) explosion, Texas, & \\
USA &
\end{tabular}

\section{In-house Acceptance Criteria for Performance Indicators}

Quantitative assessment of metrics is an integral part of the overall framework which has been used to develop a mathematical model, SPI, as shown in the following Eq. (1).

$(\mathrm{SPI})_{\mathrm{PHA}}=\left(\operatorname{LeadI}_{\mathrm{PHA}}\right)_{\mathrm{AN}} \times\left(\operatorname{LeadI}_{\mathrm{PHA}}\right)_{\mathrm{BN}} \times\left(\right.$ LeadIPHA $_{\mathrm{CN}} \times \ldots \times\left(\right.$ LeadIPHA $_{\mathrm{nN}}$

The above equation represented the scores of PHA for the particular metric for all the sections of the plant. Whereas, LeadI as expressed in Eq. (2) is the leading index for the particular metric up to metric ' $N$ ' for the sections ranging from ' $A$ ' to ' $n$ ', where $n$ is $1,2,3 \ldots$ The leading factor (LeadF) may be measured by using the following Eq. (3).

LeadI $_{\mathrm{PHA}}=\frac{\text { LeadF for a specific metric of PHA }}{\text { Average value of LeadF for all metrics of PHA }}$

$\operatorname{LeadF}_{\mathrm{PHA}}=\frac{\text { Number of implemented specific metric }}{\text { Total number of requirement for a specific metric }}$

\section{Application of The Methodology: A Case Study}

The developed methodology is applied to the case study of BP Texas City refinery explosion occurred in 2005. Despite the good key performance indicators (KPIs) of 
occupational safety, still, the disaster happened. On March 23, when restarting of a hydrocarbon isomerization unit was being carried-out, a series of explosions happened. The reason for the explosions was a flooding of a distillation tower with hydrocarbons and was over pressurized causing a geyser-like release from the vent stack. Due to mismanagement, at the time of explosions, the victims were around work trailers located near an atmospheric vent stack [39].

\section{RESULTS AND DISCUSSION}

\section{Analysis of PSM Elements}

The following analysis of past major process disasters reveals the failure in implementation of PSM elements in these disasters. Table 3 presents the number of times each process safety management (PSM) element failed for the past disasters shown in Table 1.

Table 3. Statistical analysis of process disasters.

\begin{tabular}{lc}
\hline PSM elements & No. of failures \\
\hline MI & 14 \\
PHA & 10 \\
OP & 10 \\
MOC & 9 \\
EPR & 9 \\
Training & 6 \\
HWP & 4 \\
EP & 4 \\
PSI & 3 \\
II & 2 \\
PSSR & 2 \\
CA & 1 \\
Contractors & 1 \\
TS & 1 \\
\hline
\end{tabular}

It is evident in Table 3 that mechanical integrity (MI) is the most frequently PSM element in the past disasters. However, as this element has already been taken by some other research group so next highest problematic element i.e. process hazard analysis has been considered for this research work. Furthermore, after the literature review, it has been established that there is no fixed number of indicators for any PSM element [40]. Therefore, any industrial facility should finalize their set of performance indicators according to their requirements. However, Table 4 shows some of the suggested leading and lagging indicators which may vary from industry to industry. In this way, through these indicators, safety performance will be measured and reviewed after every quarter in a year. 
Table 4. Performance metrics for PSM elements [23, 24, 41-43].

\begin{tabular}{|c|c|c|}
\hline PSM elements & Leading metrics & Lagging metrics \\
\hline EPR/OP/MI/MOC & $\begin{array}{l}\text { No. of trained } \\
\text { employees } \\
\text { No. of certified } \\
\text { leaders } \\
\text { No. of unclear } \\
\text { policies } \\
\text { No. of equipment } \\
\text { found in a good } \\
\text { testing condition }\end{array}$ & $\begin{array}{l}\text { No. of recommendations } \\
\text { per process unit } \\
\text { No. of incidents/failures } \\
\text { occurred due to faulty } \\
\text { instrumentations } \\
\text { No. of PHA/EPR/OP } \\
\text { reports available in the } \\
\text { last audit }\end{array}$ \\
\hline $\begin{array}{l}\text { Training/PSI/HWP/ } \\
\text { Contractors/PSSR }\end{array}$ & $\begin{array}{l}\text { No. of training of } \\
\text { employees on PSM } \\
\text { system } \\
\text { No. of initial and } \\
\text { refresher training } \\
\text { being conducted for } \\
\text { operators } \\
\text { No. of piping and } \\
\text { instrument diagrams } \\
\text { (P\&IDs) updated }\end{array}$ & $\begin{array}{l}\text { No. of training of } \\
\text { staff/employees on the } \\
\text { emergency management } \\
\text { system No. of violations } \\
\text { in the issuance of hot } \\
\text { work permits } \\
\text { No. of safety and health } \\
\text { notifications closed on } \\
\text { time } \\
\text { No. of procedures } \\
\text { bypassed }\end{array}$ \\
\hline EP/II/CA/TS & $\begin{array}{l}\text { Availability of } \\
\text { particular trade } \\
\text { information for } \\
\text { compiling PSI, } \\
\text { PHA, EPR, II, CA } \\
\text { and OP } \\
\text { No. of deviations } \\
\text { from the standards }\end{array}$ & $\begin{array}{l}\text { Number of } \\
\text { recommendations } \\
\text { resulting from the } \\
\text { investigations not fulfilled } \\
\text { as pointed out in the last } \\
\text { audit }\end{array}$ \\
\hline
\end{tabular}

\section{Selection of Performance Metrics for PHA}

The leading metrics for process hazard analysis (PHA) have been identified through literature review and these are seven in number. Furthermore, the consensus has been made over all these metrics through a decision-making survey tool i.e. Delphi technique so that these metrics would be implemented in all process industries. In this, the research data, i.e. opinions from experts are collected by means of two rounds of the survey in the form of questionnaires by using a 5-point Likert scale. Whereas, total around one hundred and twenty experts are elected from academics and process industries having experience in their relevant fields. 
Table 5. Leading metrics for PHA [23, 44, 45].

\begin{tabular}{|c|c|c|c|c|}
\hline Performance metrics & Section 1 & Section 2 & Section 3 & Section 4 \\
\hline $\begin{array}{l}\text { No. of unclear policies } \\
\text { related to PHA }\end{array}$ & A1 & B1 & $\mathrm{C} 1$ & D1 \\
\hline $\begin{array}{l}\text { No. of trained } \\
\text { management staff on } \\
\text { PHA }\end{array}$ & $\mathrm{A} 2$ & B2 & $\mathrm{C} 2$ & D2 \\
\hline $\begin{array}{l}\text { No. of trained team } \\
\text { members comprises of } \\
\text { engineering \& process } \\
\text { operations on PHA }\end{array}$ & A3 & B3 & C3 & D3 \\
\hline $\begin{array}{l}\text { No. of certified PHA } \\
\text { leaders }\end{array}$ & A4 & B4 & $\mathrm{C} 4$ & D4 \\
\hline $\begin{array}{l}\text { No. of PHA } \\
\text { results/assessments } \\
\text { communicated to } \\
\text { operating \& other staff } \\
\text { members for better plant } \\
\text { operations }\end{array}$ & A5 & B5 & $\mathrm{C} 5$ & D5 \\
\hline $\begin{array}{l}\text { No. of PHAs overdue for } \\
\text { revalidation }\end{array}$ & A6 & B6 & C6 & D6 \\
\hline $\begin{array}{l}\text { No. of identified hazards } \\
\text { found in PHA to be } \\
\text { mitigated or controlled }\end{array}$ & A7 & B7 & $\mathrm{C} 7$ & D7 \\
\hline $\begin{array}{l}\text { No. of PHAs conducted } \\
\text { at a regular interval of } \\
\text { time }\end{array}$ & A8 & B8 & $\mathrm{C} 8$ & D8 \\
\hline $\begin{array}{l}\text { No. of activities that } \\
\text { may affect the } \\
\text { employees }\end{array}$ & A9 & A9 & $\mathrm{C} 9$ & D9 \\
\hline $\begin{array}{l}\text { No. of engineering \& } \\
\text { administrative controls } \\
\text { availability to provide } \\
\text { early warning of a } \\
\text { catastrophic release }\end{array}$ & A 10 & B10 & $\mathrm{C} 10$ & D10 \\
\hline $\begin{array}{l}\text { No. of health \& safety } \\
\text { issues that affect } \\
\text { employees in case of any } \\
\text { failure regarding } \\
\text { engineering \& } \\
\text { administration controls }\end{array}$ & A11 & B11 & $\mathrm{C} 11$ & D11 \\
\hline
\end{tabular}

The results of both rounds of the survey have been analysed by three statistical terms i.e. $51 \%$ panellists' response belong to the $4-5$ scale, other is an interquartile range, and third is the standard deviation. At the end of the first round, the experts had no consensus on two metrics i.e. 'number of PHA results/assessments communicated to operating \& other staff members for better plant operations and Qualitative evaluation of 
safety and health effects of employees if there is a failure of engineering \& administration control'. Moreover, they also presented their four-suggested metrics which then incorporated into round two questionnaires. Hence, overall eleven leading metrics for PHA have been selected as shown in Table 5. These have been notated as A to $\mathrm{N}$ for convenience to describe in model validation section. They are helpful in providing the insights of the safety management system of any process industry. However, the industrial facility may further add performance indicators as per their requirement.

\section{Case Study 1: Validation of The Mathematical Model}

For the case study of selected Plant X, dealing in hazardous material, the leading factors according to Eq. (1) for sections A to D have been determined as shown in Table 6. In Table 6, the notations, A1 to A11, B1 to B11, C1 to C11, and D1 to D11, represent all the eleven metrics for each section A, B, C, and D respectively. Whereas, safety performance index (SPI) along with LeadI for each section have been determined according to Eq. (1), (2), and (3) respectively.

From Table 7, it is clear that the lowest value of SPI is 0.28 for which the lowest value of metric found is $\mathrm{C} 7$, having value 0.52 . Therefore, the metric, $\mathrm{C} 7$ i.e. 'number of identified hazards found in PHA to be mitigated or controlled' belongs to Section 3 needs attentiveness as it has chances to create accidents/incidents at the plant. Thus, it is suggested to carry-out safety performance review meeting after every quarter in a year to analyze the performance metrics and if they show poor performance of each identified leading and lagging indicators then intervention activity will be carried out to rectify the problem.

Table 6. LeadF calculation for performance metrics.

\begin{tabular}{|c|c|c|c|c|c|c|c|c|c|c|c|}
\hline Sect & \multicolumn{2}{|c|}{ LeadF } & Sect & \multicolumn{2}{|c|}{ LeadF } & Sect & \multicolumn{2}{|c|}{ LeadF } & Sect & \multicolumn{2}{|c|}{ LeadF } \\
\hline \multirow{11}{*}{ A } & A1 & 0.83 & & B1 & 0.80 & & $\mathrm{C} 1$ & 0.71 & & D1 & 0.90 \\
\hline & A2 & 0.90 & & B2 & 0.88 & & $\mathrm{C} 2$ & 0.80 & & D2 & 0.97 \\
\hline & A3 & 0.80 & & B3 & 0.90 & & $\mathrm{C} 3$ & 0.87 & & D3 & 0.95 \\
\hline & A4 & 0.67 & & B4 & 0.67 & & $\mathrm{C} 4$ & 1.00 & & D4 & 1.00 \\
\hline & A5 & 0.91 & & B5 & 0.92 & & C5 & 0.98 & & D5 & 0.98 \\
\hline & A6 & 0.67 & B & B6 & 0.80 & C & C6 & 0.86 & D & D6 & 0.60 \\
\hline & A7 & 0.83 & & B7 & 0.60 & & C7 & 0.43 & & D7 & 0.60 \\
\hline & A8 & 0.83 & & B8 & 0.80 & & C8 & 0.57 & & D8 & 0.60 \\
\hline & A9 & 0.93 & & B9 & 0.95 & & C9 & 0.96 & & D9 & 0.98 \\
\hline & A 10 & 0.67 & & B10 & 0.80 & & C10 & 0.86 & & D10 & 0.80 \\
\hline & A11 & 0.94 & & B11 & 0.97 & & C11 & 0.96 & & D11 & 0.87 \\
\hline Ave. & & 0.82 & & & 0.83 & & & 0.82 & & & 0.84 \\
\hline
\end{tabular}


Table 7. SPI calculation for each section.

\begin{tabular}{|c|c|c|c|c|c|c|c|c|c|c|c|c|}
\hline Sect & \multicolumn{2}{|c|}{ LeadI } & \multirow[t]{2}{*}{ Sect } & \multicolumn{2}{|c|}{ LeadI } & \multirow[t]{2}{*}{ Sect } & \multicolumn{2}{|c|}{ LeadI } & \multirow[t]{2}{*}{ Sect } & \multicolumn{2}{|l|}{ LeadI } & \multirow{2}{*}{$\begin{array}{r}\text { SPI } \\
0.93\end{array}$} \\
\hline \multirow{11}{*}{ A } & A1 & 1.02 & & B1 & 0.97 & & $\mathrm{C} 1$ & 0.87 & & D1 & 1.07 & \\
\hline & A2 & 1.10 & \multirow{10}{*}{ B } & B2 & 1.06 & \multirow{10}{*}{$\mathrm{C}$} & $\mathrm{C} 2$ & 0.98 & \multirow{10}{*}{ D } & D2 & 1.15 & 1.31 \\
\hline & A3 & 0.98 & & B3 & 1.09 & & $\mathrm{C} 3$ & 1.06 & & D3 & 1.13 & 1.28 \\
\hline & A4 & 0.82 & & B4 & 0.81 & & $\mathrm{C} 4$ & 1.22 & & D4 & 1.19 & 0.96 \\
\hline & A5 & 0.89 & & B5 & 1.11 & & C5 & 1.20 & & D5 & 1.16 & 1.74 \\
\hline & A6 & 1.02 & & B6 & 0.97 & & C6 & 1.05 & & D6 & 0.71 & 0.59 \\
\hline & A7 & 1.02 & & B7 & 0.73 & & C7 & 0.52 & & D7 & 0.71 & 0.28 \\
\hline & A8 & 1.20 & & B8 & 0.97 & & C8 & 0.70 & & D8 & 0.71 & 0.49 \\
\hline & A9 & 1.14 & & B9 & 1.15 & & C9 & 1.18 & & D9 & 1.16 & 1.79 \\
\hline & A 10 & 1.82 & & B10 & 0.97 & & C10 & 1.05 & & D10 & 0.95 & 0.79 \\
\hline & A11 & 1.15 & & B11 & 1.17 & & C11 & 1.18 & & D11 & 1.03 & 1.64 \\
\hline
\end{tabular}

\section{Statistical Analysis}

The SPI output values for leading metrics of PHA were analyzed using multiple regression routs as shown in Table 8. The equation of the fitted model is given by Eq. (4):

Table 8. Analysis of variance (ANOVA) for leading metrics of PHA.

\begin{tabular}{lccccc}
\hline Source & Sum of squares & Df & Mean square & F-ratio & P-value \\
\hline Model & 2.66512 & 4 & 0.666279 & 138.61 & 0.0000 \\
Residual & 0.0288408 & 6 & 0.0048068 & & \\
Total (Corr.) & 2.69396 & 10 & & & \\
$\mathrm{R}^{2}=98.9294 \%$ & & & & & \\
Adjusted R ${ }^{2}=98.2157 \%$ & & & & & \\
Standard error of est. $=$ & & & & & \\
0.0693311 & & & & & \\
\hline
\end{tabular}

$$
\begin{aligned}
& \mathrm{SPI}=-3.16878+1.88064 \times \text { LeadIA }_{1 \text { to1 } 11}+0.547519 \times \text { LeadIB }_{1 \text { to } 11}+1.21997 \\
& \times \text { LeadIC }_{1 \text { tol1 }}+0.593672 \times \text { LeadID }_{1 \text { tol } 1}
\end{aligned}
$$

Since the P-value in Table 8 is less than 0.05 , thus, the statistically significant relationship is found between the variables at the $95 \%$ confidence level. The coefficient of determination $\left(\mathrm{R}^{2}\right)$ indicates that the model as fitted describes $98.9 \%$ of the variability in SPI. The adjusted $\mathrm{R}^{2}$ (more suitable for comparing models with various independent variables) is $98.2 \%$. Moreover, the standard error of the estimate exhibits the standard deviation of the residuals to be 0.069 and the mean absolute error (MAE) of 0.048 is the average value of the residuals. The regression equation was tested for its ability to predict the SPI values for new data set. Thus, the multiple linear regression fits an observed dependent dataset (SPI) using four independent variables as shown in Figure 2. 


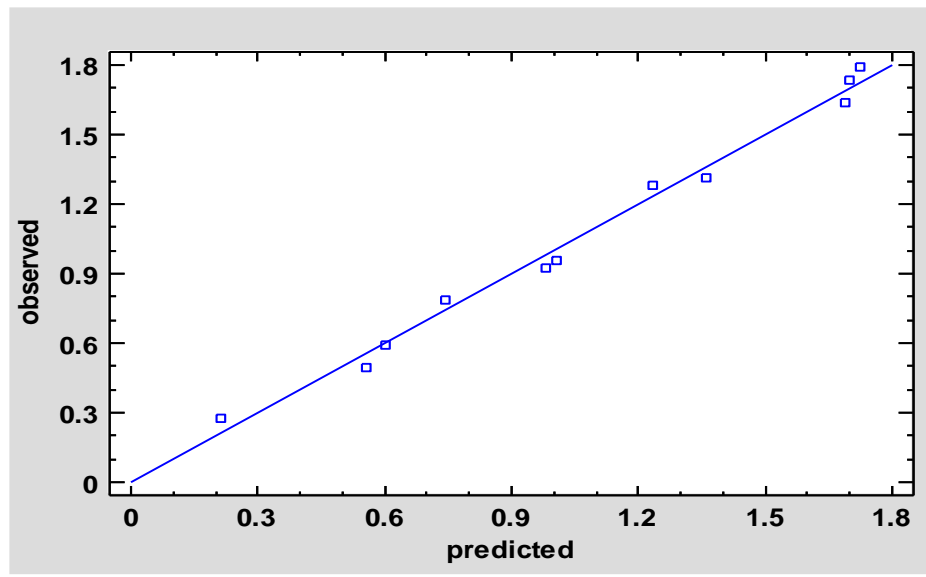

Figure 2. Predicted values versus observed values.

\section{Case Study 2: BP Texas City Refinery Explosion}

There were a number of PSM elements failed in this disaster. Firstly, a failure of process hazard analysis (PHA) element, where the major consequences of the high liquid levels in the raffinate splitter tower and the blowdown drum were not identified. Then, there was a major failure in the mechanical integrity (MI) system where many instrumentations were malfunctioning and not calibrated. The start-up procedure was not updated and not followed by the operators. Therefore, it became the cause of operating procedures (OP) element failure. Management of change (MOC) was also failed due to the wrong placement of occupied trailers. However, if the same developed safety performance framework (SPF) was in place for this refinery, then the safety performance of the whole facility would have been far much better.

\section{CONCLUSION}

The current work reveals the importance of the identification and quantitative measurement of performance metrics in order to improve safety performance. Moreover, the history of past major process disasters points out process safety management (PSM) elements as the culprit ones involved in fatal disasters. So, process industry needs to give full focus to these elements. Therefore, a score model on the basis of relative ranking approach has been developed for measuring leading and lagging metrics incorporated into a safety performance framework (SPF). It also integrates the identification of effective performance metrics which is the backbone of any industry. However, these indicators or metrics differ from industry to industry according to the requirement and need. Furthermore, two case studies i.e. one is from the current running chemical plant and other is past disaster, BP Texas City refinery explosion have been taken into consideration by using this framework. In a first case study for plant $\mathrm{X}$, the problematic unit and metric have been identified and the model has been validated through the statistical analysis of variance (ANOVA) approach. Whereas, in the second case study, the current study has found the shifting of paradigm from occupational safety to process safety after the disaster. Hence, the safety performance can now be more improved through the evaluation of performance metrics incorporated in a framework. In this way, PSM system will be worthier in any process industry in future. 


\section{ACKNOWLEDGEMENT}

The authors would like to be obliged to Universiti Teknologi PETRONAS (UTP) for providing internal research funds to make this research feasible.

\section{REFERENCES}

[1] Long LA, Marshall ML, Lay J. Update on OSHA's PSM national emphasis programs. Process Safety Progress. 2011; 30: 303-306.

[2] Kim D, Zalaya M, Mohd M, Choi H, Park K. Safety assessment of corroded jacket platform considering decommissioning event. International Journal of Automotive and Mechanical Engineering. 2017; 14: 4462-4485.

[3] Mkpat E, Reniers G, Cozzani V. Process safety education: A literature review. Journal of Loss Prevention in the Process Industries. 2018.

[4] Klein JA. Two centuries of process safety at DuPont. Process Safety Progress. 2009; 28: 114-122.

[5] Amyotte PR, Berger S, Edwards DW, Gupta JP, Hendershot DC, Khan FI, Mannan MS, and Willey RJ. Why major accidents are still occurring. Current Opinion in Chemical Engineering. 2016; 14: 1-8.

[6] Goh YM, Tan S, Lai KC. Learning from the Bhopal disaster to improve process safety management in Singapore. Process Safety and Environmental Protection. 2015; 97: 102-108.

[7] Singh B, Jukes P, Poblete B, Wittkower B. 20 Years on lessons learned from Piper Alpha. The evolution of concurrent and inherently safe design. Journal of Loss Prevention in the Process Industries. 2010; 23: 936-953.

[8] Swuste P, Groeneweg J, Van Gulijk C, Zwaard W, Lemkowitz S. Safety management systems from Three Mile Island to Piper Alpha, a review in English and Dutch literature for the period 1979 to 1988. Safety Science. 2017.

[9] Spellman FR, Bieber RM. Occupational Safety and Health Simplified for the Chemical Industry. Government Institutes. 2009.

[10] Majid NDA, Shariff AM, Rusli R. Process Safety Management (PSM) for managing contractors in process plant. Journal of Loss Prevention in the Process Industries. 2015; 37: 82-90.

[11] Luo H. The effectiveness of US OSHA process safety management inspection-A preliminary quantitative evaluation. Journal of Loss Prevention in the Process Industries. 2010; 23: 455-461.

[12] Khan F, Hashemi SJ. Introduction in Methods in Chemical Process Safety. 2017, Elsevier. p. 1-36.

[13] Majid NDA, Shariff AM, Zaki NAM. Compliance of Hot Work Permit to Process Safety Management (PSM) Regulation. Applied Mechanics and Materials. 2014; 625: 418-421.

[14] Vaughen BK, Kletz TA. Continuing our process safety management journey. Process Safety Progress. 2012; 31: 337-342.

[15] Aziz HA, Shariff AM, Zawiyah P, Rusli R. Managing Operating Procedures in Process Plant for Safe Operation. Journal of Applied Sciences. 2014; 14: 17431749. 
[16] Majid NDA, Shariff AM, Loqman SM. Ensuring emergency planning \& response meet the minimum Process Safety Management (PSM) standards requirements. Journal of Loss Prevention in the Process Industries. 2016; 40: 248-258.

[17] Majid NDA, Shariff AM, Rusli R, Azman KI. Trade Secret Model Based on OSHA Process Safety Management Requirement. Proceeding of 4th International Conference on Process Engineering and Advanced Materials (Icpeam 2016). 2016; 148: 1089-1095.

[18] Ale B. More thinking about process safety indicators. Safety Science. 2009; 47: 470-471.

[19] Qi R, Prem KP, Ng D, Rana MA, Yun G, Mannan MS. Challenges and needs for process safety in the new millennium. Process Safety and Environmental Protection. 2012; 90: 91-100.

[20] O’Mahony MT, Doolan D, O'Sullivan A, Hession M. Emergency planning and the Control of Major Accident Hazards (COMAH/Seveso II) Directive: An approach to determine the public safety zone for toxic cloud releases. Journal of hazardous materials. 2008; 154: 355-365.

[21] Berger S. History of AIChE's Center for Chemical Process Safety. Process Safety Progress. 2009; 28: 124-127.

[22] Aziz HA, Shariff AM, Rusli R. Managing process safety information based on process safety management requirements. Process Safety Progress. 2014; 33: 4148.

[23] Baker J, Bowman F, Erwin G, Gorton S, Hendershot D, Leveson N, Priest S, Rosenthal I, Tebo P, Wiegmann D. The report of the BP US refineries independent safety review panel. BP US Refineries Independent Safety Review Panel. 2007.

[24] Alnashwan M. Developing Process Safety Indicators for Organizational Factors in Petrochemical Industries. 2015.

[25] CCPS, Process Safety Leading and Lagging Metrics - You don't improve what you don't measure. New York USA; 2011.

[26] Rodante TV. Analysis of an LPG explosion and fire. Process Safety Progress. 2003; 22: 174-181.

[27] Tamim N, Laboureur DM, Mentzer RA, Hasan AR, Mannan MS. A framework for developing leading indicators for offshore drillwell blowout incidents. Process Safety and Environmental Protection. 2017; 106: 256-262.

[28] Lingard H, Hallowell M, Salas R, Pirzadeh P. Leading or lagging? Temporal analysis of safety indicators on a large infrastructure construction project. Safety Science. 2017; 91: 206-220.

[29] Wang M, Mentzer RA, Gao X, Richardson J, Mannan MS. Normalization of process safety lagging metrics. Process Safety Progress. 2013; 32: 337-345.

[30] Koteswara Reddy G, Yarakula K. Analysis of Accidents in Chemical Process Industries in the period 1998-2015. International Journal of ChemTech Research CODEN (USA): IJCRGG ISSN. 20160974-4290.

[31] Mihailidou EK, Antoniadis KD, Assael MJ. The 319 major industrial accidents since 1917. Int. Rev. Chem. Eng. 2012; 4: 529-540.

[32] Herbert I. The UK Buncefield incident-The view from a UK risk assessment engineer. Journal of Loss Prevention in the Process Industries. 2010; 23: 913-920.

[33] Rowe G, Wright G. The Delphi technique as a forecasting tool: issues and analysis. International journal of forecasting. 1999; 15: 353-375. 
[34] Christie CA, Barela E. The Delphi technique as a method for increasing inclusion in the evaluation process. Canadian Journal of Program Evaluation. 2005; 20: 105.

[35] Adler M, Ziglio E. Gazing into the oracle: The Delphi method and its application to social policy and public health. Jessica Kingsley Publishers. 1996.

[36] Skulmoski G, Hartman F, Krahn J. The Delphi method for graduate research. Journal of Information Technology Education: Research. 2007; 6: 1-21.

[37] Giannarou L, Zervas E. Using Delphi technique to build consensus in practice. International Journal of Business Science and Applied Management. 2014; 9: 6582.

[38] Hasson F, Keeney S, McKenna H. Research guidelines for the Delphi survey technique. Journal of advanced nursing. 2000; 32: 1008-1015.

[39] Besserman J, Mentzer RA. Review of global process safety regulations: United States, European Union, United Kingdom, China, India. Journal of Loss Prevention in the Process Industries. 2017; 50: 165-183.

[40] Khan F, Abunada H, John D, Benmosbah T. Development of risk-based process safety indicators. Process Safety Progress. 2010; 29: 133-143.

[41] Pasman HJ. Process safety performance indicators. Transactions of the VSBTechnical University of Ostrava, Safety Engineering Series. 2012; 7: 27-35.

[42] Reiman T, Pietikäinen E. Indicators of Safety Culture: Selection and Utilization of Leading Safety Performance Indicators. Strålsäkerhetsmyndigheten. 2010.

[43] Biggs HC, Dinsdag D, Kirk PJ, Cipolla D. Safety culture research, lead indicators, and the development of safety effectiveness indicators in the construction sector. International Journal of Technology, Knowledge and Society. 2010; 6: 133-140.

[44] Laboureur DM, Han Z, Harding BZ, Pineda A, Pittman WC, Rosas C, Jiang J, Mannan MS. Case study and lessons learned from the ammonium nitrate explosion at the West Fertilizer facility. Journal of hazardous materials. 2016; 308: 164-172.

[45] Frank W. Process safety culture in the CCPS risk based process safety model. Process Safety Progress. 2007; 26: 203-208. 